\title{
SERUM VITAMIN D LEVELS AND ITS ASSOCIATION WITH ORTHODONTIC PAIN
}

\author{
Asma Javaid ${ }^{1}$ ，Imran Tajik ${ }^{2}$, Nazir Ahmad ${ }^{3}$ ，Yasir Israr ${ }^{4}$, Siddiq Yousufi ${ }^{5}$, \\ Dr. Akbar Ali Khan ${ }^{6}$
}

\section{A6stract:}

The objective of this study was to find an association between serum Vitamin $D$ levels and pain perception in orthodontic patients after initial bond-up.

Materials and methods: Sixty four patients visiting the hospital for orthodontic treatment were included in this study. Serum vitamin D levels were checked before bondup using ELISA method. Maxillary arch bond-up was done and a 0.12 NiTI (Nickel Titanium) wire was placed for initial leveling and alignment. $\mathcal{A}$ Visual Analogue scale (VAS) was used for pain assessment on day1, 3 and 7 after initial bonding.

Results: $\mathcal{N}$ o significant correlation was found between serum vitamin $\mathcal{D}$ levels and Orthodontic pain perception on all three days. Patients with severe deficiency of vitamin $D$ gave a higher mean pain score compared to patients with mild deficiency or optimum levels. Females reported higher pain than their male counterparts in 10-20 years age group. Female patients also displayed lower mean vitamin $\mathcal{D}$ levels than their male counterparts.

Conclusion: There was no significant and direct correlation between serum Vitamin $D$ levels and the perceived level of pain by orthodontic patients. Keywords: Vitamin D level, Pain perception, Orthodontic patients.

\section{Introduction:}

Vitamin D is a hormone mainly produced by the skin in the presence of optimum sunlight. ${ }^{1}$ Other sources are natural or fortified food items and supplements that increase Vitamin D levels in the body. ${ }^{1}$ Vitamin D plays a critical role in maintaining musculoskeletal and the immune system. ${ }^{2}$ Vitamin D has been found to have anti-inflammatory effects in the body by decreasing pro-inflammatory cytokines and suppressing T-cell response. ${ }^{2}$ In-vitro studies have shown that vitamin $\mathrm{D}$ inhibits the formation of prostaglandin E2. ${ }^{3}$

A review of global vitamin D status showed widespread prevalence of vitamin D deficiency in almost every region of the world while noting concerns over data deficiency in some parts of the world mainly Asia and Africa. ${ }^{4}$ Optimal serum level of 25-hydroxy vitamin D (25- $(\mathrm{OH}) \mathrm{D})$ is $>25 \mathrm{ng} / \mathrm{ml}^{4}{ }^{4}$ While levels below $30 \mathrm{ng} / \mathrm{ml}$ are prevalent in most populations, levels below $10 \mathrm{ng} / \mathrm{ml}$ that expresses severe vitamin $\mathrm{D}$ deficiency are most commonly seen in populations at risk. ${ }^{4}$ In some regions, such as South Asia and Middle East, severe vitamin D deficiency has been commonly found in both sexes and all age groups. ${ }^{4,5}$

Recent observational studies indicate an association between low vitamin D levels and increased pain as well as higher opioid dose consumption in post -op patients. ${ }^{6}$ Interventional studies have also shown positive effects of vitamin D supplementation on cancer pain and muscular pain-especially in patients with insufficient levels of vitamin $D$ when starting intervention. ${ }^{7}$ Possible mechanisms for vitamin $D$ in pain management are the antiinflammatory effects mediated by reduced

\footnotetext{
${ }^{1}$ Resident, Department of Orthodontics, Sardar Begam Dental Hospital, Peshawar, Pakistan]

2- Professor and Head of Orthodontics Department, Sardar Begam dental hospital, Peshawar

3- Professor, Department of Orthodontics, Sardar Begum Dental Hospital.

4- Resident, Department of Orthodontics. Sardar Begam Dental Hospital, Peshawar.

5- Resident, Department of Orthodontics. Khyber college of Dentistry, Peshawar.

6- Assistant Professor, Department of Orthodontics Sardar Begum Dental Hospital
} 
cytokine and prostaglandin release. , $6,7^{-1}$

Orthodontic treatment with fixed appliances is frequently associated with pain and discomfort. $^{8}$ Pain typically initiates within 4 hours, increases over the next 24 hours, and gradually reduces within 7 days after initial bonding. ${ }^{8}$ The pain and discomfort in orthodontic treatment are due to multiple factors such as pressure, ischemia and inflammation associated with tooth movement. ${ }^{8}$ Vitamin D in orthodontics have been studied for its potential stimulation of osteoclastic activity and its role in increasing orthodontic tooth movement. ${ }^{9,10}$

No previous studies associating vitamin D and its effect on orthodontic pain perception could be found in literature. The purpose of our study was to find if there is any association between orthodontic pain perception and serum vitamin D levels in patients undergoing orthodontic treatment.

Materials and Methods:

A total of 64 patients were selected for this study, from the Department of Orthodontics, Sardar Begam Dental Hospital Peshawar, Pakistan, from November 2019 to April 2021.The participants were consecutive patients who visited the hospital for orthodontic treatment and were enrolled in the study if all inclusion criteria were satisfied and an informed consent was obtained.

The inclusion criteria were:

(1) Twelve to twenty-five years old male or female patient who required orthodontic treatment.

(2) Completely erupted permanent dentition till permanent first molars

(3) A minimum crowding of $4 \mathrm{~mm}$ in maxillary arch.
Exclusion criteria were patients presenting with any of the following;

(1) Any underlying medical condition, congenital syndromes or systemic diseases.

(2) History of chronic pain in the oro-facial region or dental pain.

(3) History of being surgically operated.

(4) Previous history of Vitamin D prescription by a physician.

(5) Previous history of extraction

(6) Previous history of orthodontic treatment with any appliance having dental or orthopaedic effect.

(7) Previous history of being hospitalized following severe trauma.

(8) Patients who took analgesics in one week after the bond up were excluded from the study.

On the day of bond up the patients were referred to the laboratory for assessment of 25$(\mathrm{OH})$ vitamin D levels. Serum 25- $(\mathrm{OH})$ D level was measured in nanograms per millilitre (ng/ml) by enzyme linked immune-sorbent assay (ELISA) method.

The patients were then bonded with MBT prescription from the right molar to left molar in the upper arch and a $0.12 \mathrm{NiTi}$ (Nickel Titanium) wire was placed for initial levelling and alignment. The bond up of all the patients was done between 9-11 am. A questionnaire for pain assessment was given to the patients with a VAS calibrated from $0-10$ for pain assessment on day 1 , day 3 and day 7 , where 0 indicated no pain and 10 indicated the worst pain imaginable.

A detailed explanation of the pain scale was also given to the patients individually. In case of unbearable pain; the patients were advised to take analgesics (Ibuprofen or Paracetamol) and such patients were then excluded from the 
study. Reminders as text messages and calls were given to the patients on days 1,3 and 7 . The vitamin D assessment report and the questionnaires were collected from the patients on the eighth day of bond up. For ease of analysis Vitamin D levels were categorized as 1-10ng/ml (severe deficiency), $10-25 \mathrm{ng} / \mathrm{ml}$ (mild deficiency) and $>25 \mathrm{ng} / \mathrm{ml}$ (optimum levels), the widely used thresholds in the South Asian population. ${ }^{11}$

\section{Data analysis:}

All the data obtained was recorded on a data collection form designed for this study. For statistical analysis we used SPSS version 20.0.0. ANOVA (Analysis of Variance) was used to see the difference between subcategories of vitamin D and pain levels. Pearson's Correlation test was applied to measure correlation between variables. The level of statistical significance was set at $\mathrm{P}<0.05$.

\section{Results}

The mean age of the sample was $18.12+-5.8$ years. Among the participants 17 were male and 47 were females. The descriptive statistics of pain scores and vitamin D levels are shown in Table 1.

The average pain scores on three days $(1,3$, and 7) in different vitamin D categories are shown in Fig-1. Participants in all groups experienced significant discomfort on day 1 which receded to mild discomfort on day 7 , for most of the participants. (Fig-1). Patients in severe vitamin D deficiency group showed increased average pain scores than patients with optimum vitamin D levels.( Fig-1)

A comparison of pain scores on different days $(1,3$, and 7$)$ in different vitamin D categories showed no statistically significant difference among all categories as shown in Table 2.

Figure 2 shows pain perception on all three days $(1,3$, and 7$)$ in different age groups in both genders, which shows an increased pain perception by female patients than males, in both age groups (Fig-2)

Pearson Correlation test was used to check any possible association between pain scores and vitamin D levels on all three days, however the result was statistically not significant as shown in Table 3.

A negative correlation however was seen between pain scores and vitamin D levels on all three days as shown in Table-3, the correlation value being highest on day 1 and lowest on day 3 .

The Scatterplots in Figure 3, 4 and 5 shows the pain perception in relation to vitamin $\mathrm{D}$ levels on day 1, day 3 and day 7 of bond up showing their strength of association.

Table 1: Descriptive statistics for pain and Vitamin $D$ levels

\begin{tabular}{|c|c|c|c|c|c|}
\hline & $\mathrm{N}$ & Mean & $\begin{array}{c}\text { Standard } \\
\text { deviation }\end{array}$ & Min & Max \\
\hline $\begin{array}{c}\text { Vitamin D } \\
\text { levels }\end{array}$ & 64 & $17.21 \mathrm{ng} / \mathrm{ml}$ & 8.99 & $4.6 \mathrm{ng} / \mathrm{ml}$ & $51.80 \mathrm{ng} / \mathrm{ml}$ \\
\hline Pain Day 1 & 64 & 5.44 & 3.10 & 0 & 10 \\
\hline Pain Day 3 & 64 & 3.13 & 2.54 & 0 & 10 \\
\hline Pain Day 7 & 64 & 1.47 & 2.17 & 0 & 10 \\
\hline
\end{tabular}


Table 2: Pain perception on day 1,3 and 7 in different vitamin $D$ categories

\begin{tabular}{|c|c|c|c|c|c|c|}
\hline $\begin{array}{c}\text { Pain } \\
\text { on } \\
\text { days }\end{array}$ & $\begin{array}{l}\text { Vitamin D } \\
\text { categories. }\end{array}$ & $\mathbf{N}$ & Mean & $\begin{array}{c}\text { Std. } \\
\text { Deviation }\end{array}$ & $\begin{array}{c}95 \% \\
\text { Confidence } \\
\text { interval }\end{array}$ & P value \\
\hline \multirow{3}{*}{$\begin{array}{l}\text { Pain } \\
\text { D1 }\end{array}$} & $0-10$ & 36 & 5.89 & 3.27 & \multirow{3}{*}{$4.92-6.95$} & \multirow{3}{*}{0.418} \\
\hline & $10.1-25$ & 18 & 4.89 & 3.16 & & \\
\hline & $>25$ & 10 & 4.80 & 1.93 & & \\
\hline \multirow{3}{*}{$\begin{array}{c}\text { Pain } \\
\text { D3 }\end{array}$} & $0-10$ & 36 & 3.44 & 2.11 & \multirow{3}{*}{$2.62-4.73$} & \multirow{3}{*}{0.301} \\
\hline & $10.1-25$ & 18 & 2.33 & 2.67 & & \\
\hline & $>25$ & 10 & 3.40 & 3.53 & & \\
\hline \multirow{3}{*}{$\begin{array}{c}\text { Pain } \\
\text { D7 }\end{array}$} & $0-10$ & 36 & 1.89 & 2.18 & \multirow{3}{*}{$0.53-2.31$} & \multirow{3}{*}{0.216} \\
\hline & $10.1-25$ & 18 & 0.89 & 2.39 & & \\
\hline & $>25$ & 10 & 1.00 & 1.414 & & \\
\hline
\end{tabular}

*One way ANOVA

$* * \mathrm{P}$ value $<0.05$ was taken as significant.

NOVA test was applied.

Table-3: Correlation between serum vitamin $D$ level and pain perception.

\begin{tabular}{|l|l|l|l|}
\hline & N & $\begin{array}{c}\text { Pearson } \\
\text { Correlation }\end{array}$ & P value \\
\hline Day 1 & 64 & -0.215 & 0.088 \\
\hline Day 3 & 64 & -0.101 & 0.428 \\
\hline Day 7 & 64 & -0.082 & 0.519 \\
\hline
\end{tabular}

*Pearson correlation test was applied.

$* * \mathrm{P}$ value $<0.05$ was taken as significant. 


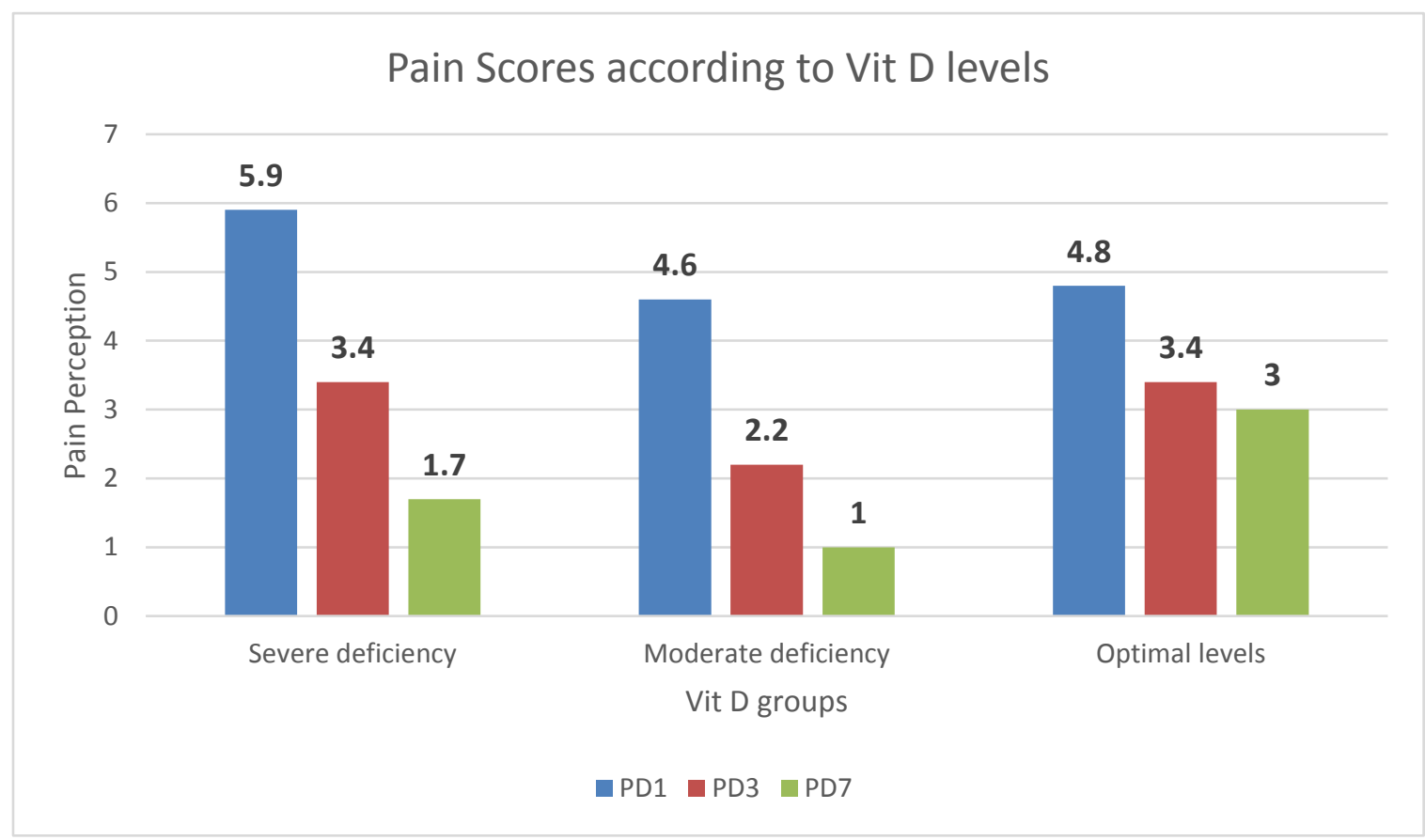

Figure 1: Average pain scores on different days in different categories of vitamin D PD1=Pain day 1, PD2=Pain day 2, PD3=Pain $\operatorname{dav} 3$
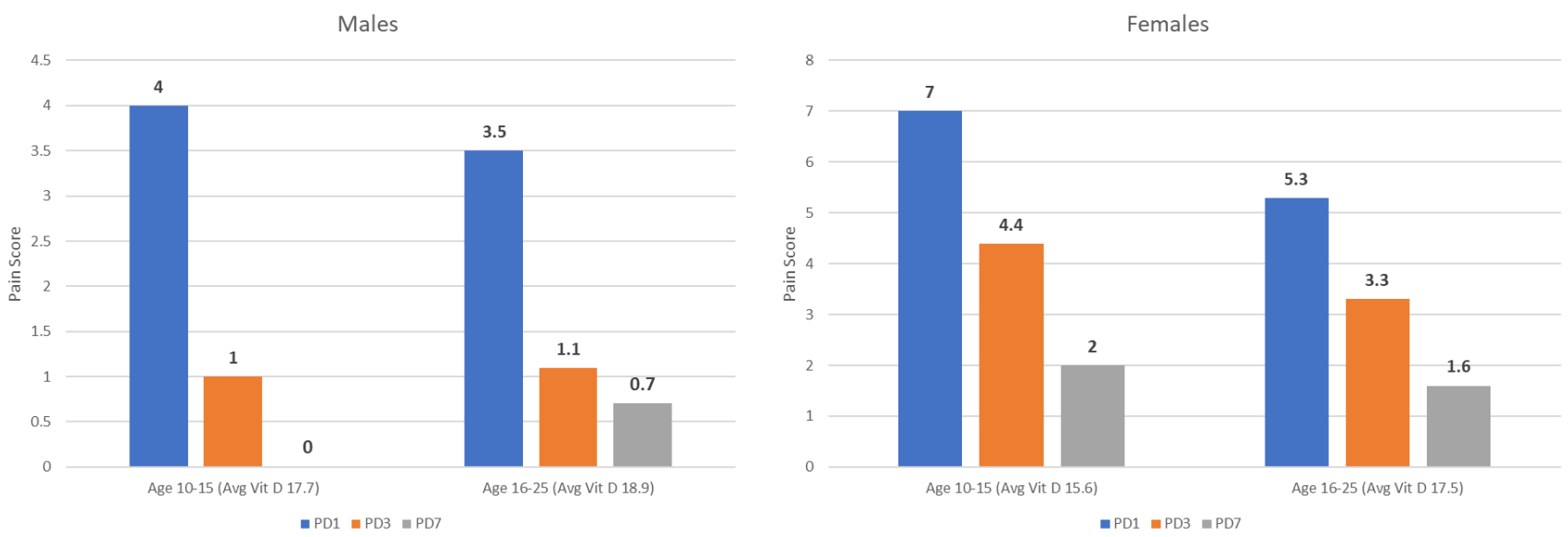

Figure 2: Average pain scores on different days in different age groups and both genders. PD1=Pain day1, PD2=Pain day 2, PD3= Pain day 3 


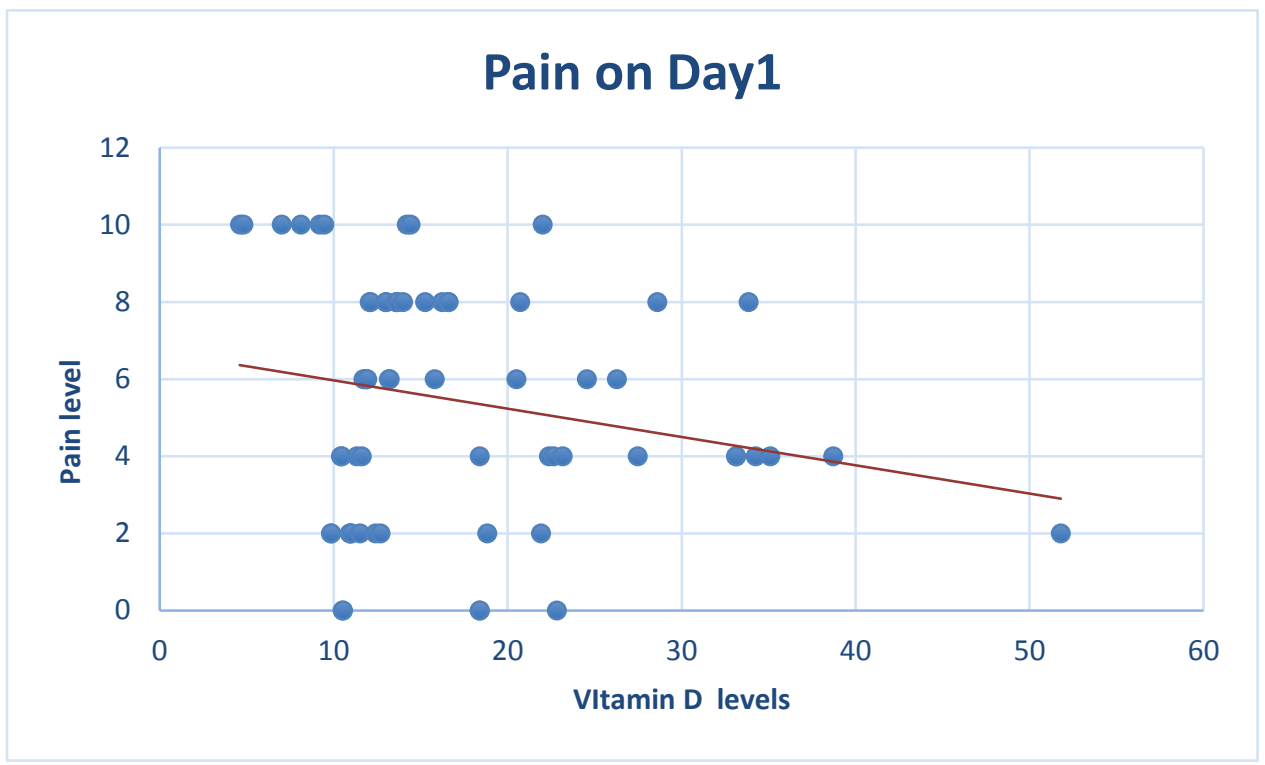

Figure 3: Association between pain and vitamin D levels on Day1 in all patients

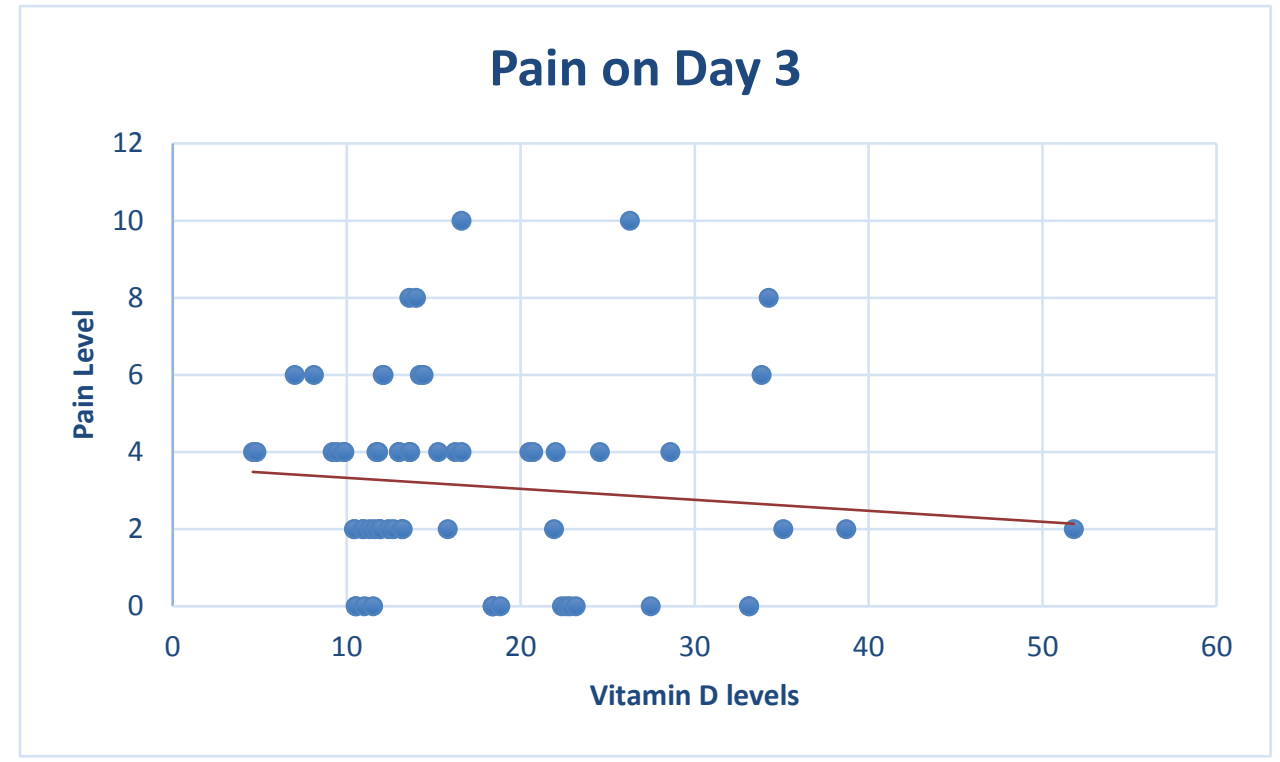

Figure 4: Association between pain and vitamin D levels on Day 3 in all patients. 


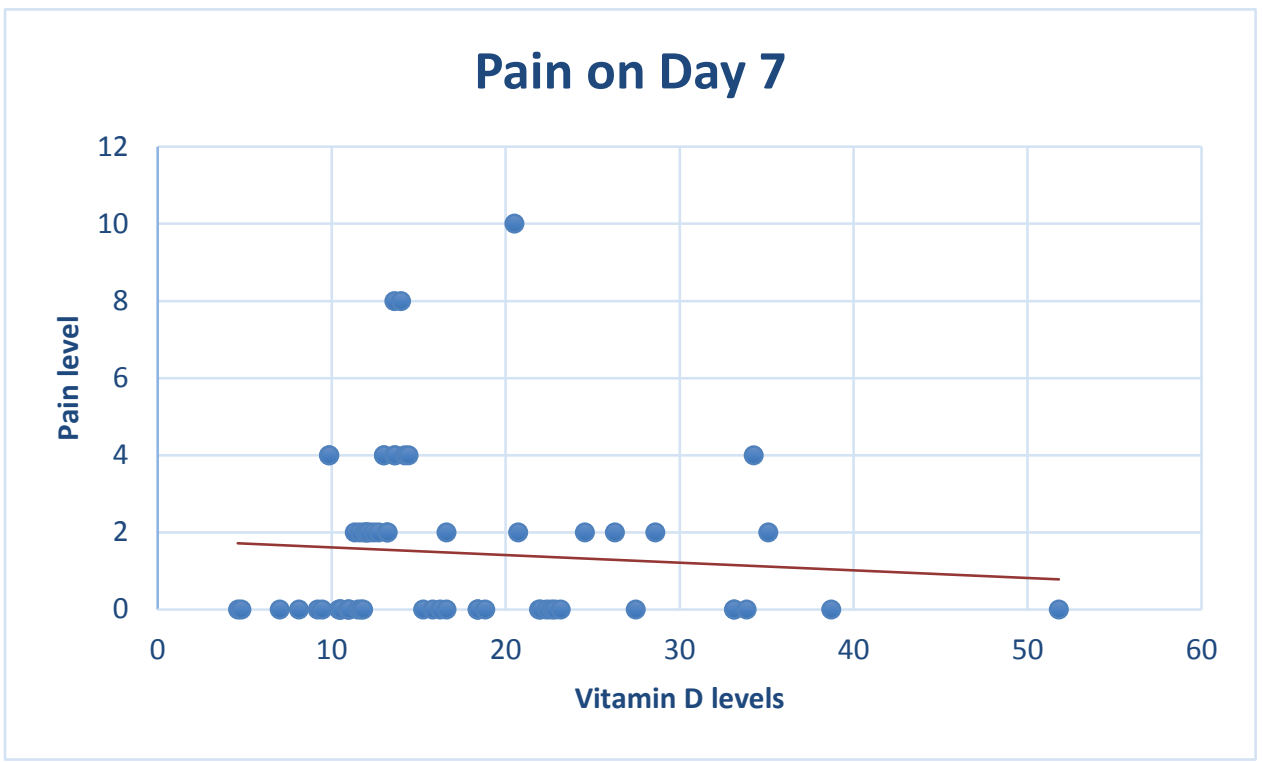

Figure 5: Association between pain and vitamin D levels on Day 7 in all patients.

\section{Discussion:}

This study was carried out to look for a possible association between orthodontic pain and serum Vitamin D levels of patients undergoing orthodontic treatment. The cut-off vitamin D levels for mild, moderate and severe deficiency is a matter of intense controversy as its serum levels depend on the climate, customs, cultural setup and diet. There is a diverging difference among the absolute standard for various geographical zones, however there is general consensus that values $<25 \mathrm{nmol} / \mathrm{l} \quad(10 \mathrm{ng} / \mathrm{ml})$ indicate severe deficiency and $\geqslant 50 \mathrm{nmol} / \mathrm{l}(20 \mathrm{ng} / \mathrm{ml})$ indicate sufficiency. ${ }^{4,5,11}$

In our study we found a negative but insignificant correlation between vitamin D levels and the pain perception recorded by respective patients on day 1 , day 3 and day 7 (Fig 3,4 and 5). Patients who fell in the range of mild to moderate deficiency $(10-25 \mathrm{ng} / \mathrm{ml})$ or Optimum levels $(>25 \mathrm{ng} / \mathrm{ml})$ showed a lesser average pain score on all three days compared to severely deficient patients $(<10 \mathrm{ng} / \mathrm{ml})$. In all three groups, the average pain score were higher on day 1 , which gradually decreased on day 3 , and were minimum on day 7.Our results are in coherence with other studies that assessed vitamin D levels and pain association in clinical setups and reported that levels below normal pre operatively increased the risk of moderate-to-severe persistent pain post operatively. ${ }^{12,13}$ Studies have also reported mood enhancement, better sleeping habits, decreased pain levels and general well-being after vitamin D supplementation. ${ }^{14-16}$

Our results indicated that females in age groups of 10-16years gave higher scores on all three days of pain assessment than their male counterparts but also had lower mean Vitamin D levels (Fig 2). Our results are in agreement with other research findings that indicate increased Orthodontic pain perception by adolescent females especially those in 14-17 years of age as compared to males. ${ }^{17}$ There was a disparity between Vitamin D levels in both genders as boys displayed considerably higher levels of Vitamin D. The mean vitamin D 
values for males and females were 21.82 and 17.6 respectively. In our sample size this can be because boys are not confined to their homes as opposed to females in the sociocultural norms of the South Asian community. ${ }^{5}$ The findings in our study are in agreement with Sadhu-et al who assessed pain perception in orthodontic patients and concluded that female patients experienced greater orthodontic pain than male patients and that this difference gradually increases with age. ${ }^{17}$ The trend in our results suggests that in female patients with decreasing vitamin D levels, the reported average pain score increased. Our result is in agreement with a number of studies displaying a significant correlation between deficiency of Vitamin D and both skeletal and muscular pain, where-in the reported pain levels were much more in females. ${ }^{6}$

However a number of other studies have indicated varying results on evaluating the effects of vitamin D in states of chronic pain. ${ }^{18}$

Even though Pain is a highly varying phenomenon, in our study maximum effort was made to assess patients with no previous history of trauma or invasive dental treatment. The underlying vitamin D levels of patients seeking orthodontic treatment need to be assessed in a greater sample of various populations. $^{4,19}$

\section{Limitations:}

Our major limitation was a small sample size. So a study on a bigger population sample is recommended. ${ }^{20}$

Conclusions

$>$ No significant relation was found between vitamin $D$ and pain scores.

> Average pain scores were higher in severe vitamin $D$ deficiency group compared to those with optimum levels.
Female patients reported increased pain score than male counterparts.

$>$ Mean vitamin D level was higher in males than females.

\section{REFERENCES:}

1. Hewison M. Antibacterial effects of vitamin D. Nat Rev Endocrinol. 2011;7(6):337-345.

doi:10.1038/nrendo.2010.226

2. Wang T-T, Nestel FP, Bourdeau V, et al. Cutting Edge: 1,25-Dihydroxyvitamin D 3 Is a Direct Inducer of Antimicrobial Peptide Gene Expression . J Immunol. 2004;173(5):2909-2912.

doi:10.4049/jimmunol.173.5.2909

3. Liu $X$, Nelson A, Wang $X$, et al. Vitamin D Modulates PGE2 Synthesis and Degradation in Human Lung Fibroblasts. Am $J$ Respir Cell Mol Biol. August 2013:130813135401001. doi:10.1165/rcmb.2013-0211OC

4. Mithal A, Wahl DA, Bonjour JP, et al. Global vitamin $\mathrm{D}$ status and determinants of hypovitaminosis D. Osteoporos Int. 2009;20(11):1807-1820. doi:10.1007/s00198009-0954-6

5. Faiza S, Zaman LMS, Iftikhar A, Sadia B, Saif U, Nauman K. Vitamin D deficiency in Pakistani population: critical overview from 2008 to 2018. Nutr Food Sci. 2019;50(1):105-115. doi:10.1108/NFS-032019-0105

6. Helde-Frankling M, BjörkhemBergman L. Vitamin D in pain management. Int $J \quad$ Mol Sci. 2017;18(10):1-9. doi:10.3390/ijms 18102170

7. Shipton EA, Shipton EE. Vitamin D and pain: Vitamin $\mathrm{D}$ and its role in the aetiology and maintenance of chronic pain states and associated comorbidities. Pain Res 
Treat. 2015;2015. doi:10.1155/2015/904967

8. Hussain AS, Al Toubity MJ, Elias WY. Methodologies in Orthodontic Pain Management: A Review. Open Dent J. 2017;11(1):492-497.

doi:10.2174/1874210601711010492

9. Collins MK, Sinclair PM. The local use of vitamin $D$ to increase the rate of orthodontic tooth movement. Am J Orthod Dentofac Orthop. 1988;94(4):278-284. doi:10.1016/0889-5406(88)90052-2

10. Almoammar K. Vitamin D and orthodontics: An insight review. Clin Cosmet Investig Dent. 2018;10:165-170. doi:10.2147/CCIDE.S157840

11. Lowe NM, Bhojani I. Special considerations for vitamin $\mathrm{D}$ in the south Asian population in the UK. Ther $A d v$ Musculoskelet Dis. 2017;9(6):137-144. doi:10.1177/1759720X17704430

12. Lee A, Chan SKC, Samy W, Chiu CH, Gin T. Effect of hypovitaminosis $d$ on postoperative pain outcomes and short-term health-related quality of life after knee arthroplasty. Med (United States). 2015;94(42):e1812.

doi:10.1097/MD.0000000000001812

13. Oteri G, Cicciu M, Peditto M, et al. Does vitamin D3 have an impact on clinical and biochemical parameters related to third molar surgery. J Craniofac Surg. 2016;27(2):469-476. doi:10.1097/SCS.0000000000002389

14. Spedding S. Vitamin D and depression: A systematic review and meta-analysis comparing studies with and without biological flaws. Nutrients. 2014;6(4):1501-
1518. doi:10.3390/nu6041501

15. Huang W, Shah S, Long Q, Crankshaw AK, Tangpricha V. Improvement of pain, sleep, and quality of life in chronic pain patients with vitamin D supplementation. Clin $J \quad$ Pain. 2013;29(4):341-347. doi:10.1097/AJP.0b013e318255655d

16. Vieth R, Kimball S, Hu A, Walfish PG. Randomized comparison of the effects of the vitamin D3 adequate intake versus $100 \mathrm{mcg}$ (4000 IU) per day on biochemical responses and the wellbeing of patients. Nutr J. 2004;3. doi:10.1186/1475-2891-3-8

17. Sandhu SS, Sandhu J. Orthodontic pain: an interaction between age and sex in early and middle adolescence. Angle Orthod. 2013;83(6):966-972. doi:10.2319/030113174.1

18. Shipton EE, Shipton EA. Vitamin D Deficiency and Pain: Clinical Evidence of Low Levels of Vitamin D and Supplementation in Chronic Pain States. Pain Ther. 2015;4(1):67-87. doi:10.1007/s40122015-0036-8

19. Riaz H, Finlayson AE, Bashir S, et al. Prevalence of Vitamin D deficiency in Pakistan and implications for the future. Expert Rev Clin Pharmacol. 2016;9(2):329338. doi:10.1586/17512433.2016.1122519

20. González-Fernández $\mathrm{M}$, Ghosh $\mathrm{N}$, Ellison T, McLeod JC, Pelletier CA, Williams K. Moving beyond the limitations of the visual analog scale for measuring pain: novel use of the general labeled magnitude scale in a clinical setting. Am J Phys Med Rehabil. 2014;93(1):75-81. doi:10.1097/PHM.0b013e31829e76f7 